EESTI NSV TEADUSTE AKADEEMIA TOIMETISED.

FOOSIKA * MATEMAATIKA

ИЗВЕСТИЯ АКАДЕМИИ НАУК ЭСТОНСКОИ ССР. ФИЗИКА - МАТЕМАТИКА

PROCEEDINGS OF THE ACADEMY OF SCIENCES OF THE ESTONIAN SSR.

PHYSICS * MATHEMATICS

$1986,35,1$

удк $517.94+519.46+539.12$

A. AINSAAR, K. KIIRANEN

\title{
GROUP ANALYSIS OF SOME ORDINARY DIFFERENTIAL EQUATIONS
}

\author{
(Presented by $H$. Keres)
}

\section{Introduction}

Proceeding from a given evolution equation, the group analysis enables one to open its physical contents and can obtain the laws of conservation $\left[{ }^{1,2}\right]$. A more academic problem is to seek for the proper physical equation. Then the symmetry properties are usually of primary importance and the problem is reversed. Recently the role of field-space-time symmetry (hodograph invariance) was pointed out in that respect $\left[{ }^{3,4}\right]$. Though the space-time is four-dimensional and the isotopic space in elementary particle physics is usually taken as three-dimensional, for some reasons, like simplicity, a rich variety of soliton solutions etc., simple ordinary-differential equations are paid much attention to by physicists $\left[{ }^{5-8}\right]$.

The problem of the classification of differential equations by means of the groups of the Lie point transformations admissible by these equations was posed and developed by L. V. Ovsyannikov [ $\left.{ }^{\circ}\right]$. The approach consists in taking the equation dependent on certain parameters or functions. The group, admissible by this equation, materially depends on the choice of these parameters or functions.

Here the ordinary differential equations of the form

$$
u_{x x}=a(u)
$$

are considered in this respect. We also investigate the problem of finding the transformations between differential equations. The transformations between two particular cases of equation (1);

$$
u_{x x}=u
$$

and

$$
v_{t t}=0
$$

are given. By using these transformations one can find the generators of the Lie-Bäcklund transformations of equation (2), starting from those of equation (3). Independently, the Lie-Bäcklund transformations of equation (2) can be obtained by using suitably chosen power series.

It is interesting that equations (2) and (3) are in one-to-one correspondence with their groups.

\section{Classification of equations (1)}

We can get the generators $X=\xi(x, u) \frac{\partial}{\partial x}+\zeta(x, u) \frac{\partial}{\partial u}$ of the point 
transformation group of equations (1) by using the method of Lie and Ovsyannikov $\left[{ }^{9}\right]$. The system of determining equations is

$$
\begin{aligned}
\xi u u & =0, \\
\zeta_{u u}-2 \xi_{x u} & =0, \\
2 \zeta_{x u}-\xi_{x x}-3 a \xi_{u} & =0, \\
\xi_{x x}+a\left(\zeta_{u}-2 \xi_{x}\right)-a^{\prime} \zeta & =0 .
\end{aligned}
$$

Equations (4a), (4b) which do not contain the function $a(u)$, have the solution

$$
\begin{aligned}
& \xi=\alpha(x) u+\beta(x), \\
& \zeta=\alpha_{x}(x) u^{2}+\gamma(x) u+\delta(x),
\end{aligned}
$$

where $\alpha, \beta, \gamma$ and $\delta$ are functions of $x$, which, like $a(u)$, can be determined from equations (4c) and (4d). Equation (4c) leads to

$$
a \cdot a^{\prime \prime}=0 \text {. }
$$

Here one has to consider two possibilities 1) $a^{\prime \prime} \neq 0$.

Equations (4c) and (4b) read now

$$
\begin{gathered}
\beta_{x}=2 \gamma-c, \quad(c=\text { const }), \\
u \gamma_{x x}+\delta_{x x}+(2 c-3 \gamma) a-\left(u_{\gamma}+\delta\right) a^{\prime}=0 .
\end{gathered}
$$

Double differentiation of $(7 \mathrm{~b})$ with respect to $u$ gives

$$
a^{\prime \prime}(2 c-5 \gamma)=a^{\prime \prime \prime}(u \gamma+\delta) \text {. }
$$

Starting from these equations one can differ the following cases a) $\gamma=0, \quad \delta \neq 0$.

In this case the function is restricted to

$$
a(u)=a_{0} e^{\lambda u}, \quad\left(a_{0} \neq 0, \lambda \neq 0\right) .
$$

The generators, admitted by equation (1), are

$$
X_{1}=\frac{\partial}{\partial x}, \quad X_{2}=x \frac{\partial}{\partial x}-\frac{2}{\lambda} \frac{\partial}{\partial u}
$$

b) $\gamma \neq 0, \quad \delta=0$.

Here one gets

$$
a(u)=a_{0} u^{n} ; \quad\left(a_{0} \neq 0, n \neq 0,1\right) .
$$

As to the group admitted by equation (1) there are two possibilities $n=-3$.

Then $\gamma_{x x}=0$ and there are three group generators -

$$
X_{1}=\frac{\partial}{\partial x}, \quad X_{2}=2 x \frac{\partial}{\partial x}+u \frac{\partial}{\partial u}, \quad X_{3}=x\left(x \frac{\partial}{\partial x}+u \frac{\partial}{\partial u}\right),
$$
$n \neq-3$.

Then $\gamma=\frac{2 c}{n+3}$ and the generators are

$$
X_{1}=\frac{\partial}{\partial x}, \quad X_{2}=(1-n) x \frac{\partial}{\partial x}+2 u \frac{\partial}{\partial u},
$$

c) $\gamma \neq 0, \quad \delta \neq 0$. 
This case leads to the similar results (11)-(13) with the substitution

d) $\gamma=0, \quad \delta=0$.

$$
u \rightarrow u+x, \quad(x=\text { const } \neq 0),
$$

These equations admit only one transformation - the shift $X=\frac{\partial}{\partial x}$.

2) $a^{\prime \prime}=0$.

This is the only case where the group of the Lie point transformations, admitted by equation (1); is maximal, having 8 parameters.

For example, equation (2) admits the following generators -

$$
\begin{gathered}
X_{1}=\frac{\partial}{\partial x}, \quad X_{2,3}=e^{ \pm x} \frac{\partial}{\partial u}, \quad X_{4}=u \frac{\partial}{\partial u}, \\
X_{5,6}=e^{ \pm 2 x}\left(u \frac{\partial}{\partial u} \mp \frac{\partial}{\partial x}\right), \quad X_{7,8}=u e^{ \pm x}\left(u \frac{\partial}{\partial u} \mp \frac{\partial}{\partial x}\right) .
\end{gathered}
$$

Equation (3) admits the generators

$$
\begin{aligned}
& X_{1}=\frac{\partial}{\partial t}, \quad X_{2}=\frac{\partial}{\partial v}, \quad X_{3}=t \frac{\partial}{\partial t}, \quad X_{4}=v \frac{\partial}{\partial v}, \\
& X_{5}=t \frac{\partial}{\partial v} ; \quad X_{6}=v \frac{\partial}{\partial t}, \\
& X_{7}=v\left(t \frac{\partial}{\partial t}+v \frac{\partial}{\partial v}\right), \quad X_{8}=t\left(t \frac{\partial}{\partial t}+v \frac{\partial}{\partial v}\right) .
\end{aligned}
$$

Both equation (3) and system (15) are hodograph invariants [3,4].

In conclusion, in the case of equation (1) the only possible point transformation groups are of $1,2,3$, and 8 parameters. In effect there are 6 different groups. As we shall see later, the groups, corresponding to equations (2) and (3), can be transformed into each other by point transformations.

\section{Transformations between equations}

We pose a problem of finding the transformations which link two given equations. In particular, the question includes the problem of linearization of nonlinear differential equations $\left[{ }^{10,11}\right]$.

Here we confine ourselves to ordinary differential equations and point transformations, although the results can also be generalized to, firstly; partial differential equations and, secondly, to tangent transformations.

Let us have two ordinary differential equations of second order -

$$
\begin{aligned}
& \omega_{1}\left(v, v_{t}, v_{t t}\right)=0, \\
& \omega_{2}\left(u, u_{x}, u_{x x}\right)=0 .
\end{aligned}
$$

We seek for general conditions under which these equations can be transformed into each other by a point transformation

$$
\begin{aligned}
& x=X(t, v), \\
& u=U(t, v) .
\end{aligned}
$$

For that purpose we express the derivatives of $u$ in terms of variables $t, v, v_{t}, v_{t t}-$

$$
u_{x}=\frac{D_{t} U}{D_{t} X} \equiv A\left(t, v, v_{t}\right),
$$




$$
u_{x x}=\frac{D_{t}^{2} U \cdot D_{t} X-D_{t}^{2} X \cdot D_{t} U}{\left(D_{t} X\right)^{3}} \equiv B\left(t, v, v_{t}, v_{t t}\right)
$$

where $D_{t} \equiv \frac{\partial}{\partial t}+v_{t} \frac{\partial}{\partial v}+v_{t t} \frac{\partial}{\partial v_{t}}+\ldots$, and insert these in equation (17). As a result we get the determining equation for the functions $X$ and $U-$

$$
\left.\omega_{2}\left[U(t, v), A\left(t, v, v_{t}\right), B\left(t, v, v_{t}, v_{t t}\right)\right]\right|_{\omega_{t}=0}=0 .
$$

The inverse transformations

$$
\begin{aligned}
& t=T(x, u), \\
& v=V(x, u) ;
\end{aligned}
$$

can be found analogically.

In the previous section we had two equations, (2) and (3). Different powers of $v_{t}$ in equation (21) give

$$
\begin{aligned}
& X_{t} U_{t t}-U_{t} X_{t t}=X_{t}^{3} U \\
& X_{v} U_{v v}-U_{v} X_{v v}=X_{v}^{3} U \\
& X_{v} U_{t t}-U_{v} X_{t i}+2\left(X_{t} U_{v t}-U_{t} X_{v t}\right)=3 X_{v} X_{t}^{2} U \\
& X_{t} U_{v v}-U_{t} X_{v v}+2\left(X_{v} U_{v t}-U_{v} X_{v t}\right)=3 X_{t} X_{v}^{2} U
\end{aligned}
$$

One can easily check that equations $(23)$ have the solution

$$
\begin{aligned}
& X=\frac{1}{2} \ln \left(\frac{v+t}{v-t}\right), \\
& U=\left(v^{2}-t^{2}\right)^{-1 / 2} .
\end{aligned}
$$

The corresponding inverse transformations (22) are*

$$
\begin{aligned}
& T=\frac{\operatorname{sh} x}{u} \\
& V=\frac{\operatorname{ch} x}{u} .
\end{aligned}
$$

If one assumes [ $\left.{ }^{7}\right]$ that $t=T(x)$, then we get instead of (25)

$$
\begin{aligned}
& T=\operatorname{th} x, \\
& V=\frac{u}{\operatorname{ch} x} .
\end{aligned}
$$

The variables $t, \alpha, \beta$ introduced in [ $\left.{ }^{8}\right]$ actually correspond to tangent transformations

$$
\begin{aligned}
& t=T(x) \equiv x \\
& v=V\left(x, u, u_{x}\right) \equiv u \operatorname{ch} x-u_{x} \operatorname{sh} x \\
& v_{t}=V_{1}\left(x, u, u_{x}\right) \equiv u_{x} \operatorname{ch} x-u \operatorname{sh} x
\end{aligned}
$$

* In general, $T=\frac{u_{1}(x)}{u}, V=\frac{u_{2}(x)}{u}$, where $u_{1}, u_{2}$ are two different solutions of (2). 
Thus, we can see that the only equation of form (1) which can be taken into form (3) by point transformations; is (2).

\section{Lie-Bäcklund algebra}

There are lots of equations which admit nontrivial Lie-Bäcklund ( $\mathrm{L}-\mathrm{B})$ algebras [ $\left.{ }^{1}\right]$. Usually, finding point transformations is not difficult, but the $\mathrm{L}-\mathrm{B}$ transformations, as a rule, pose a serious problem.

The equation for determining the generators

$$
X=f\left(t, v, v_{t}, \ldots\right) \frac{\partial}{\partial v}
$$

of $\mathrm{L}-\mathrm{B}$ transformations of equation (3) is simple -

$$
f_{t i}+2 v_{t} f_{t v}+v_{t}^{2} f_{v v}=0,
$$

a general solution of which is $\left.{ }^{1}\right]-$

$$
f=v \cdot g\left(v-v_{t} \cdot t, v_{t}\right)+h\left(v-v_{t} \cdot t, v_{t}\right),
$$

where $g$ and $h$ are arbitrary functions of the arguments indicated. Thus; there are only contact transformations. A particular choice of $g$ and $h$ leads ot the generators of point transformations (15).

The equation for determining the generators

$$
Y=\varphi\left(x, u, u_{x}, \ldots\right) \frac{\partial}{\partial u}
$$

of the $\mathrm{L}-\mathrm{B}$ transformations of equation (2) is more complicated -

$$
\begin{gathered}
\varphi_{x x}+p^{2} \varphi_{u u}+u^{2} \varphi_{p p}+2 p_{\varphi_{x u}}+2 u \varphi_{x p}+ \\
+2 u \varphi_{\varphi_{u p}}+p_{\varphi_{p}}+u_{\varphi}-\varphi=0 \quad\left(p \equiv u_{x}\right) ;
\end{gathered}
$$

where, taking into account equation (2) together with its differential consequences, $\varphi$ depends only on $x, u$ and $p$.

It is convenient to seek for a solution of this equation in the form of power series and a Laplace integral

$$
\varphi=\int \sum_{i, j=0}^{\infty} C_{k i j} e^{k x} u^{i} p^{j} d k .
$$

In (32) the coefficient of any term $e^{k x} u^{m} p^{n}$ has to vanish:

$$
\begin{aligned}
& \left(2 m n+m+n+k^{2}-1\right) C_{k m n}+2 k(n+1) C_{k(m-1)(n+1)}+ \\
& +2 k(m+1) C_{k(m+1)(n-1)}+(n+2)(n+1) C_{k(m-2)(n+2)}+ \\
& +(m+2)(m+1) C_{k(m+2)(n-2)=0}
\end{aligned}
$$

where $C_{k m n}=0$ when $m<0$ or $n<0$. Now for anv chosen integer nonnegative values of $m+n$ one obtains fixed values for $k$ and the integral in (33) turns into a sum.

For example, in the case $m+n=1$ either $m=1$ and $n=0$ or $m=0$ and $n=1$ and (34) reads

$$
\begin{aligned}
& k^{2} C_{k 10}+2 k C_{k 01}=0, \\
& 2 k C_{k 10}+k^{2} C_{k 01}=0,
\end{aligned}
$$


from which $k_{1,2}= \pm 2 ; k_{3}=0$, and the corresponding solutions are

$$
\varphi=e^{ \pm 2 x}(p \mp u), \varphi=u \text { and } \varphi=p .
$$

By changing $m+n$, one can get an infinite set of generators (31), the first ones being given by the functions:

$$
\begin{aligned}
& \varphi_{1,2}=e^{ \pm x}, \\
& \varphi_{3}=p, \\
& \varphi_{4}=u, \\
& \varphi_{5,6}=e^{ \pm 2 x}(u \mp p), \\
& \varphi_{7,8}=e^{ \pm x} u(u \mp p), \\
& \varphi_{9,10}=e^{ \pm x} p(p \mp u), \\
& \varphi_{11,12}=e^{ \pm 3 x}(u \mp p)^{2}, \\
& \varphi_{13}=p\left(p^{2}-u^{2}\right) ; \\
& \varphi_{14}=u\left(u^{2}-p^{2}\right), \\
& \varphi_{15,16}=e^{ \pm 4 x}(u \mp p)^{3}, \\
& \varphi_{17,18}=e^{ \pm 2 x}\left(u^{2}-p^{2}\right)(u \mp p), \\
& \varphi_{19,20}=e^{ \pm 2 x}(u \mp p)^{3},
\end{aligned}
$$

Here $\varphi_{1}, \ldots, \varphi_{8}$ leads to the generators of point transformations in the canonical form obtained above. All other $\varphi_{i}$ give nontrivial contact transformations.

We can see that $u$ and $p$ are symmetrically involved. This proves natural if equation (2) is taken in its equivalent form $u_{x}=p, p_{x}=u$. The $\mathrm{L}-\mathrm{B}$ algebras of these equations are isomorphic [ $\left.{ }^{2}\right]$.

There is also another possibility to find the $\mathrm{L}-\mathrm{B}$ transformations. Let equations (16) and (17) be connected by point transformations (18) and let $\mathrm{L}-\mathrm{B}$ transformations (28) of one of these, (16), be known. Then we can also find the generators (31) of the $\mathrm{L}-\mathrm{B}$ transformations of the other equation, (17), as

$$
\varphi\left(x, u ; u_{x}, \ldots\right)=\left.f\left(t, v, v_{t}, \ldots\right)\left(U_{v}-u_{x} X_{v}\right)\right|_{(22)} .
$$

In the given example with transformations (24) and (25) we get

$$
\varphi(x, u, p)=(p \operatorname{sh} x-u \operatorname{ch} x)(\operatorname{ch} x \cdot g(\xi, \eta)+u \cdot h(\xi, \eta)),
$$

where

$$
\begin{aligned}
& \xi=(u \operatorname{ch} x-p \operatorname{sh} x)^{-1}, \\
& \eta=\frac{u \operatorname{sh} x-p \operatorname{ch} x}{u \operatorname{ch} x-p \operatorname{sh} x} .
\end{aligned}
$$

In a particular case we can also obtain the known generators (35) by this method. For example, if $g=0$ and $h=-2$, then one gets $\varphi=\varphi_{7}+\varphi_{8}$.

Such problem is also investigated in $\left.{ }^{7}\right]$, where transformations (26) are used. At that, (36) gives

$$
\varphi=u \cdot g(\xi ; \eta)+\operatorname{ch} x \cdot h(\xi, \eta),
$$

where $\xi=u \operatorname{ch} x-p \operatorname{sh} x, \eta=p \operatorname{ch} x-u \operatorname{sh} x$. 


\section{Correspondence between equations and groups}

An equation uniquely determines the group of point transformations, i.e. the corresponding generators. But, in principle, different equations may admit the same group.

Still, it is known that there are equations that are uniquely determined by their groups and order. Such is, for instance, the Monge-Ampere equation $\left[{ }^{12}\right]$.

In order to examine our equations in this respect, we make use of the second extensions $\tilde{X}_{i}$ of generators (14) and (15). The identities [ $\left.{ }^{13}\right]$

$$
\left.\widetilde{X}_{i \omega}(x, u, p ; r)\right|_{\omega=0}=0 \quad\left(i=1, \ldots, 8, p \equiv u_{x}, r \equiv u_{x x}\right)
$$

following from generators (15) lead to $\omega=r$, but for (14) one gets $\omega=$ $=r-u$. Thus, we can see that equations (2) and (3) are uniquely determined by their symmetry groups.

\section{Conclusions and acknowledgements}

Considering different equations with isomorphic point groups, one can make use of the point transformations between these equations. Knowing the generators of the L-B transformations of one of the equations, one can obtain that of the other ones.

A generalization to tangent transformations is complicated by the fact that inverse transformations must be used there, perhaps nonlocal variables $\left[{ }^{14}\right]$ have to be introduced in the $\mathrm{L}-\mathrm{B}$ transformations.

The authors are grateful to $M$. Kõiv and V. Rosenhaus for fruitful discussions.

\section{REFERENCES}

1. Anderson, R. L., Ibragimov, N. H. Lie-Bäcklund Transformations in Applications. SIAM, Philadelphia, 1979.

2. Ибрагимов H. X. Группы преобразований в математической физике. М., «Наука», 1983.

3. Ainsaar, A.. Kõiv, M. ENSV TA Toim. Füüs. Matem.. 28, № 4, 294-301 (1979).

4. Kồiv, M., Ainsaar, A., Kiiranen, K. Preprint F-15. Tartu, 1981.

5. Ланкерович М. Я. В кн.: Дннамнка сплошной среды. Вып. 37. Новосибирск, 1978, $133-138$.

6. Meinhardt. J. J. Phys. A: Math. Gen. 14, 1893-1914 (1981).

7. Martini, R., Kersten, P. H. M. Phys. A: Math. Gen., 16, L455-460 (1983).

8. Polyanov, L. V., Voronin, A. I. J. Phys. A: Math. Gen., 17, 1787-1790 (1984).

9. Овсянников Л. В. Групповой анализ дифференциальных уравнений. М., «Наука», 1978.

10. Фущщч B. Н., Тычинин B. А. Препринт 82.33, Институт математики АН УССР. Кнев, 1982.

11. Kumei, S., Bluman, G. W. SIAM J. Appl. Math., 42, № 5, 1157-1173 (1982).

12. Rosenhaus, V. Preprint F-18. Tartu, 1982.

13. Bluman, G. W.. Cole, J. D. Appl. Math. Sci., 13 (1974).

14. Cullen, J., Reid, J. J. Phys. A: Math. Gen., 16. 1889-1909 (1983).

Academy of Sciences of the Estonian SSR,

Received

Institute of Physics

Feb, 25, 1985 


\section{MONEDE HARILIKE DIFERENTSIAALVORRANDITE RUHMAANALUUS}

Artiklis on käsitletud harilike diferentsiaalvõrrandite $u_{x x}=a(u)$ näitel järgmisi küsimusi: võrrandite poolt lubatud punktteisenduste rühmade leidmist, võrrandite spetsialisatsiooni nende abil, kahe antud võrrandi vaheliste teisenduste leidmist ning nende võrrandite Lie-Bäcklundi teisenduste vahelist seost, samuti võrrandite ja rühmade üksühese vastavuse probleemi.

\section{A. АИНСААР, К. КИИРАНЕН}

\section{ГРУППОВОИ АНАЛИЗ НЕКОТОРЫХ ОБЫКНОВЕННЫХ ДИФФЕРЕНЦИАЛЬНЫХ УРАВНЕНИИ}

На примере обычных дифференциальных уравнений типа $u_{x x}=a(u)$ рассматриваются следующие вопросы: нахождение групп точечных преобразований, допускающихся этими уравнениями, специализация этих уравнений, нахождение преобразований между двумя уравнениями и связи между преобразованиями Ли-Беклунда этих уравнений, а также проблема однозначного соответствия между уравнениями и группами. 